\title{
Produção editorial e comunicação científica: uma proposta para edição de revistas científicas
}

\section{Ana Cláudia Gruszynski, Cida Golin e Raquel Castedo}

\section{Resumo}

A produção editorial contemporânea revela as tensões existentes entre 0 tradicional mundo impresso, com limites físicos de informação, e 0 espaço on-line como um contínuo informativo. Problematizando o cenário da comunicação científica, este artigo apresenta os resultados finais da pesquisa $O s$ elementos comunicacionais dos periódicos científicos e a relação com os suportes impresso e on-line: estudo-piloto na UFRGS. A partir da perspectiva da produção editorial, propõe dois roteiros para orientação das comissões editoriais na edição, consolidação e qualificação de periódicos científicos impressos e eletrônicos.

\section{Palavras-chave}

Produção editorial. Comunicação científica. Revistas científicas. Periódicos científicos. UFRGS.

\section{Ana Cláudia Gruszynski I anagru@gmail.com}

Professora do Programa de Pós-Graduação em Comunicação e Informação da Universidade Federal do Rio Grande do Sul - UFRGS.

\section{Cida Golin I cidago@terra.com.br}

Professora do Programa de Pós-Graduação em Comunicação e Informação da UFRGS.

\section{Raquel Castedo | raquelcastedo@yahoo.com}

Mestranda do Programa de Pós-Graduação em Comunicação e Informação da UFRGS.

\section{Introdução}

A comunicação em rede e a tecnologia digital vêm desestabilizando práticas que orientaram a produção editorial ao longo do século XX. Do planejamento de seus processos à circulação de produtos cada vez mais diversificados e dirigidos, são muitos os desafios impostos aos profissionais envolvidos nessa atividade. Refletir sobre a prática editorial, contudo, não é apenas lidar com um conjunto de técnicas e estratégias voltadas à produção de livros e periódicos. É colocar-se diante de artefatos que armazenam e fazem circular o conhecimento humano, articulando em seu entorno fatores econômicos, sociais, simbólicos, estreitamente relacionados a dinâmicas de poder e de disputas.

A tecnologia responsável pela produção de impressos e sua apropriação por diferentes grupos sociais estabelecidos em espaços temporais e geográficos distintos representou um importante fator na configuração das práticas editoriais. Ao propor uma história social do conhecimento entre 0 Renascimento e 0 Iluminismo, Burke (2003) enfatiza o papel crucial 
da invenção da imprensa com tipos móveis, tecnologia que ampliou a difusão dos saberes, facilitando a interação entre pessoas em lugares e culturas distintas por meio do acesso a um mesmo padrão de texto e imagem.

Bragança (2005), em notas para uma constituição da história do editor, trata do trabalho pioneiro dos impressores-editores e dos livreiros-editores, discutindo sobre seu papel emergente no século XV. A consolidação do ofício envolveu questões de custo, organização institucional, estabelecimento e gerenciamento de direitos sobre 0 que era publicado, seleção de textos, censura, modos de circulação e aprimoramento tecnológico, que configuraram o perfil do editor-empresário no século XIX. Ao longo da primeira metade do século $\mathrm{XX}$, o desenvolvimento da cultura impressa ocorre "sob a hegemonia do editor-empresário e das instituições escolares e nacionais" (BRAGANÇA, 2005, p. 232), característica que entra em crise no período seguinte a partir do surgimento e fortalecimento dos meios audiovisuais. Novas estratégias editoriais buscaram assegurar a sustentação das empresas dedicadas à edição. A partir de 1935, por exemplo, a ampliação do repertório de edições de bolso resultou na formação de grandes editoras dedicadas ao pocket book de alta qualidade editorial.

0 surgimento dos meios digitais e da Internet repercutiu fortemente em um campo regido pela tradição, exigindo a reavaliação de critérios e parâmetros que sempre orientaram sua práticas.
A atividade editorial - ao lidar com a escrita em diferentes suportes - tem como elemento fundamental a materialidade dos artefatos por ela gerados, que se constituem como parte inalienável das representações, revelando a importância da edição e da impressão na constituição da cultura gráfica. Nesse sentido, Lyons (1999) argumenta que a forma física do texto (na tela ou no papel), o seu formato e a disposição do espaço tipográfico na página são fatores que determinam a relação histórica entre leitor e texto. Vemos, por exemplo, que o livro impresso herdou várias convenções do manuscrito, mas gradativamente desenvolveu sua própria sistemática de configuração das páginas. Os elementos que compõem sua interface são resultado de um processo histórico, onde formas que hoje nos parecem naturais baseiam-se na apropriação de técnicas datadas e transitórias.

Assim como a configuração gráfica, as práticas de leitura ao longo do tempo são experiências que envolvem aspectos sociais e individuais, desde expectativas de leituras, competências e gêneros de textos lidos. Para Chartier (1996), o ato de ler resulta de tensões estabelecidas entre dois conjuntos de fatores: os relacionados aos leitores e às comunidades de interpretação nas quais estão inseridos; e aqueles que envolvem os textos e a sua materialidade. Portanto, ao propormos uma reflexão sobre um produto específico gerado por meio de uma atividade editorial, entendemos ser fundamental a consideração de tais fatores que contextualizam nosso objeto de análise. 
As práticas editoriais associadas aos periódicos científicos impressos e eletrônicos na contemporaneidade nos colocam diante de um gênero de publicação que circula em um espaço social singular - a comunidade científica, os pares e que se configuram inicialmente segundo estrutura e função surgidas no século XVII. Segundo Houghton (1975), os primeiros periódicos científicos Journal des Sçavans e Philosophical Transaction - datam de 1665. Ambos contribuíram como modelos diferentes para a literatura científica: 0 primeiro influenciou o desenvolvimento das revistas dedicadas à ciência geral, sem comprometimento com uma área específica, e o segundo se tornou modelo das publicações das sociedades científicas, que apareceram em grande número na Europa durante o século XVIII (STUMPF, 1998).

Meadows (1999) aponta várias razões para 0 surgimento dos periódicos científicos na segunda metade do século XVII. Entre elas, a esperança de editores em obter lucro com as revistas, e a crença de que para fazer novos descobrimentos era preciso que houvesse um debate coletivo. No entanto, o motivo principal, segundo o autor, partiu da necessidade de comunicação eficiente com uma clientela que crescia rapidamente interessada em novas realizações. Apesar da introdução da revista científica impressa ser um passo lógico para a época, isso suscitava implicações notáveis para a ciência, uma vez que significava a formalização do processo de comunicação científica. Os canais existentes para a comunicação científica no século
XVII - principalmente a comunicação oral, a correspondência pessoal e os livros - foram todos, em certa medida, modificados ou até mesmo substituídos gradativamente pelo nova modalidade formal constituída pelos periódicos.

0 formato das revistas científicas manteve-se praticamente inalterado nos últimos séculos. Somente a partir da segunda metade do século $\mathrm{XX}$, com 0 avanço da tecnologia, o perfil das revistas começou a mudar efetivamente. Na década de 60, o uso de microfilmes, em substituição às cópias em papel, surgiu como possibilidade para reduzir 0 custo das assinaturas e da remessa, além de diminuir o espaço de armazenamento dos periódicos (STUMPF, 1998). A alternativa não foi bem aceita, nem por assinantes particulares, nem pelos usuários das bibliotecas, sendo hoje utilizada apenas como uma forma de obtenção de volumes antigos. A partir da década de 70, os avanços da editoração eletrônica foram capazes de trazer maior qualidade e rapidez na editoração. Entre as tentativas de informatizar todo o processo editorial, destacam-se os projetos de Editorial Processing Centers (EPC), desenvolvido nos Estados Unidos, e Birmingham and Loughborough Eletronic Network Development (BLEND), da Inglaterra. A grande mudança, contudo, ocorre a partir da década de 1990 com 0 início da transmissão eletrônica de artigos por meio da Internet. A gênese dos periódicos científicos eletrônicos está ligada à comunicação que ocorria por meio de cartas (e-mails) e 
pequenos jornais dirigidos (newsletters), que gradualmente se deslocou para esse outro meio.

\section{0 campo científico e a produção de periódicos}

0 periódico científico, no processo de comunicação da ciência, funciona como uma das instâncias de consagração. Ao atuar como um filtro seletivo, reproduzindo as sanções e exigências próprias do campo científico, confere valor às pesquisas e as situa no seu grau de originalidade em relação ao conhecimento já acumulado em determinada área do conhecimento. Vários autores (MEADOWS, 1999; STUMPF, 1996; BIOJONE, 2003; MARCHIORI; ADAMI, 2005) corroboram que o modelo ideal de periódico é um instrumental qualitativo. Garante a memória da ciência, aponta seu grau de evolução, estabelece a propriedade intelectual, legitima novos campos de estudos e disciplinas, constitui-se em fonte para o início de novas pesquisas, dando visibilidade e prestígio aos pesquisadores entre um público altamente especializado, os seus pares.

Na medida em que não existe investigação sem estratégias específicas de divulgação de seus resultados, ou seja, de reconhecimento entre os pesquisadores-concorrentes de um mesmo segmento, o periódico científico assume o papel de principal veículo formal da comunicação científica (BOURDIEU, 1983; OLIVEIRA, 2005). Ao reunir pelo menos parte da produção mais representativa dos campos de estudo, as revistas são utilizadas como indicadores para avaliação de cursos de pós-graduação, concessão de bolsas, progressão funcional, entre outros. Atuam como índices nos sistemas de julgamento que configuram as estruturas institucionais de pesquisa e, conseqüentemente, dos mecanismos decisórios de poder e distribuição de verbas destinadas a ela.

A partir de sua teoria dos campos, Bourdieu (1983) apresenta o campo científico como um lugar onde ocorrem lutas pelo monopólio da autoridade, ou seja, pela competência científica, compreendida como a capacidade de um agente em falar e agir de maneira autorizada e com autoridade. As práticas estabelecidas no jogo concorrencial estão voltadas à construção daquilo que é percebido, a partir do próprio campo, como importante e interessante, logo, com maiores chances de reconhecimento.

Nesse cenário descrito por Bourdieu (1983), a publicação dos resultados de pesquisa em periódicos de reconhecimento colocase como uma das formas fundamentais de luta por autoridade científica (reputação e prestígio) entre um público seleto de leitores concorrentes. Desse modo, a qualificação das revistas científicas, preocupação constante de suas equipes editoriais, ganha a atenção dos pesquisadores/autores, que, tendo acesso a esses títulos, procuram colaborar com as edições de maior qualidade e visibilidade. A busca permanente pela criação de critérios de qualidade para periódicos, difundida no Brasil 
a partir da década de 1960, aparece ao mesmo tempo como conseqüência e constante incentivo aos pesquisadores pela divulgação de seus artigos nos mais respeitados veículos.

Na medida em que o reconhecimento científico orienta a produção das revistas, os critérios de avaliação dessas publicações científicas ditam as metas a serem alcançadas pelas equipes editoriais. Enquanto os periódicos científicos existiram apenas no papel, a identificação de critérios para a avaliação e comparação de desempenho manteve a coerência das possibilidades de produção vista a partir de um único suporte. A criação dos formatos eletrônicos, no entanto, impulsionou a migração do impresso para o espaço on-line; diversos títulos ganharam versões híbridas (eletrônica e impressa) e outros tantos já nasceram na Internet, desafiando o estabelecimento de novos parâmetros de qualidade para esse tipo de publicação.

\section{Do impresso ao on-line}

A comunicação por meio de periódicos científicos eletrônicos vem se ampliando significativamente nos últimos anos. Dados como os da pesquisa efetuada por Lawrence (2001) apontam que a circulação eletrônica dos artigos aumenta cerca de $336 \%$ as citações on-line em relação à mesma fonte impressa e referendam a busca pela visibilidade e pelo prestígio em um campo especializado e competitivo. Quase três séculos depois da criação da primeira revista científica impressa, surge, em 1978, a primeira revista científica eletrônica, financiada pela National Science Foundation e desenvolvida no New Jersey Institute of Technology, nos Estados Unidos da América (TARGINO, 1999). Desde então, mudanças, adaptações e avanços permeiam o desenvolvimento de revistas científicas eletrônicas.

A primeira vantagem vista pelos editores de títulos científicos disponibilizados na Internet, apresentados ainda com layout nos moldes das revistas impressas, foi a alteração na distribuição e visibilidade das edições. Já é possível, entretanto, pensar em um outro nível de transformação da comunicação científica que se percebe na etapa de produção dessas publicações. Não se trata apenas do uso da tecnologia digital a fim de otimizar o processo de edição, com o uso de softwares de editoração, troca de dados via e-mail ou disponibilização de forma eletrônica do conteúdo criado para ser impresso - entre tantos outros facilitadores -, mas sim da utilização dessa tecnologia na criação de novos modelos de comunicação das informações científicas.

Dedicado ao estudo dos periódicos científicos eletrônicos, Lancaster (1995) descreve quatro etapas de sua evolução. No início da década de 1960, o incipiente uso de computadores gerava publicações impressas convencionais, possibilitando impressões por demanda e customizadas a partir das necessidades de cada leitor. Em seguida, o texto passa a ser distribuído eletronicamente em versão similar ao papel. A terceira fase consistiu na distribuição de periódicos apenas em formato eletrônico; nesse caso, a 
publicação avançou um pouco mais com a utilização de ferramentas de busca e manipulação de dados, além de alerta aos leitores de que foram publicados artigos de seu interesse, a partir do cadastro de seus perfis. 0 quarto momento descrito compreende a geração de um tipo de publicação completamente novo, que explora as reais potencialidades do meio eletrônico, como por exemplo, o hipertexto informático, incorporando som, fala, ruídos, gráficos, desenhos, fotos, vídeos, etc.

0 autor argumenta que, apesar desses quatro passos serem considerados lógicos no processo evolutivo, é difícil descrever em que fase se encontra a maioria das revistas, uma vez que todas as etapas coexistem atualmente. Por outro lado, o último estágio descrito por Lancaster (1995) ainda não estaria completamente atingido, já que pouquíssimos são os autores preocupados em produzir material concebido especificamente para publicação on-line.

\section{Periódicos em transição: um estudo de caso da UFRGS}

Com o objetivo de verificar os elementos

editoriais e gráficos das revistas editadas pelas áreas de Ciências Humanas, Ciências Sociais Aplicadas, Lingüística, Letras e Artes, publicadas entre 2003 e 2004 pela Universidade Federal do Rio Grande do Sul, a pesquisa Os elementos comunicacionais dos periódicos científicos e a relação com os suportes impresso e on-line: estudo-piloto na UFRGS $S^{1}$ problematizou aspectos técnicos, semânticos e persuasivos relacionados à comunicação científica por meio de periódicos. Percebeu-se no conjunto de 23 títulos analisados o cenário contemporâneo desse tipo de publicação: a migração do suporte tradicional impresso para o eletrônico, sinalizando impasses e lacunas dessa transição, assim como as novas estratégias de visibilidade do conhecimento.

A coexistência das fases apontadas por Lancaster (1995) no corpus avaliado demonstrou que ainda há vários desafios e ser vencidos pelas publicações da Universidade no sentido de qualificar a comunicação por meio de periódicos em seus diferentes níveis estruturais (GRUSZYNSKI; GOLIN, 2006; GRUSZYNSKI; GOLIN, 2007; GRUSZYNSKI; GOLIN; LUCCHESE, 2007). A partir da análise efetuada, a equipe elaborou dois roteiros um relacionado aos periódicos impressos e outro aos on-line que visam orientar as comissões editoriais na gestão dos vários procedimentos que abrangem a publicação de revistas científicas.

0 trabalho de pesquisa desenvolvido entre 2005 e 2007 levou em consideração que a avaliação de periódicos tem sido objeto de pesquisas desde a década de 60, envolvendo a busca de parâmetros para dimensionar a qualidade das informações registradas. 0 estudo realizado por Kryzanowski e Ferreira (1998), que analisou os periódicos sob 
os aspectos de forma e mérito (desempenho e conteúdo), serviu como referência para a Coordenação de Aperfeiçoamento de Pessoal de Nível Superior (CAPES) do Ministério da Educação (MEC) para a classificação das publicações nos últimos anos. ${ }^{2}$

Outros roteiros voltados para avaliação de periódicos foram desenvolvidos por Sarmento e Souza, Foresti e Vidotti (2004), que elaboraram um protótipo específico para a publicação eletrônica que foi utilizado para análise de dois títulos disponíveis gratuitamente na Internet da área de Ciências da Informação; e Trzesniak (2006), que definiu critérios de análise tanto para impressos e eletrônicos, a partir de quatro dimensões de qualidade: técnico-normativa; finalidade de produto; qualidade de mercado; processo produtivo, destacando, no caso do eletrônico, aspectos essenciais como busca, preservação e metadados. ${ }^{3}$

Enquanto os roteiros elaborados por esses pesquisadores visaram estabelecer critérios para avaliar os periódicos científicos, considerando o que estava consolidado no produto editorial pronto e publicado, procuramos enfatizar 0 outro pólo da produção editorial, ou seja, o planejamento, o estabelecimento de fluxos de edição, bem como a definição de estratégias de circulação. Entendemos que essa poderia ser uma contribuição singular dos estudos da Comunicação junto a um tema que vem recebendo atenção de pesquisadores vinculados majoritariamente ao campo das Ciências da Informação. As revistas são editadas por pesquisadores especialistas em seus campos, mas que muitas vezes não detêm o conhecimento dos processos de produção editorial. Portanto, as comissões podem encontrar nos roteiros que propomos a seguir - um voltado para o meio impresso e outro para o on-line - orientações a respeito dos diferentes aspectos que devem ser observados e sistematizados na edição de periódicos científicos, visando sua consolidação e qualificação.

Como foi discutido ao longo do presente artigo, estamos em um momento de intensas e rápidas mudanças no âmbito da produção editorial, em particular daquelas associadas à comunicação científica. Entendemos que os itens reunidos e sistematizados nos roteiros propostos correspondem a demandas de um período histórico específico caracterizado pela crise do modelo clássico de produção, distribuição e consumo dos periódicos científicos. Esse processo passa pela inevitável migração do suporte tradicional impresso para o eletrônico, sinalizando mudanças tanto no mercado editorial como nas estratégias de visibilidade do conhecimento.

0 Sistema Qualis <http://qualis.capes.gov.br.> avaliou os periódicos das diferentes áreas em categorias A, B e C dentro dos âmbitos local, nacional e internacional.

Pode-se citar ainda os trabalhos de Oliveira (2005), bem como Mendonça, Fachin e Varvakis (2006). 
Vejamos, então, na Figura 1 as orientações

direcionadas aos periódicos impressos e na

Figura 2 aquelas direcionadas aos eletrônicos,

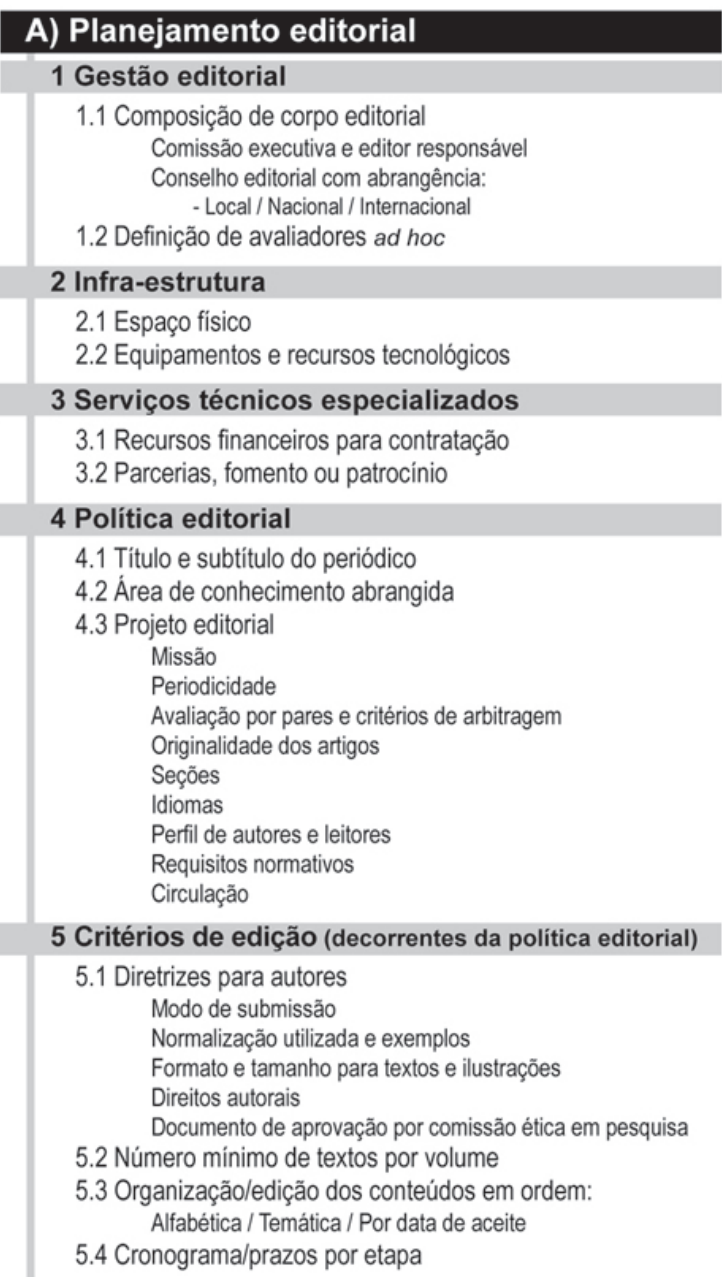

\section{B) Fluxo editorial}

\section{Edição de texto}

1.1 Avaliação pelos pares

1.2 Mediante aceite, revisão ortográfica e gramatical

1.3 Mediante aceite, normalização técnica

Elementos que devem constar no fasciculo - Dados de identificação do periódico

$$
\text { Titulo }
$$

ISSN elou E-ISSN

Dados para contato

- Dados de identificação do fasciculo

Legenda bibliográfica

Ficha catalográfica

Código de barras

- Instituição responsável

Dados institucionais

Fontes de apoio/patrocinio

- Dados sobre gestão e política editorial

Nominata de membros

Missão

Periodicidade

Avaliaçăo por pares e critérios de arbitragem

Diretrizes para submissão

Propriedade do direito autoral para, a seguir, explicitarmos com maior

detalhamento os itens apresentados. Enfatizamos

nos roteiros três etapas fundamentais - 0

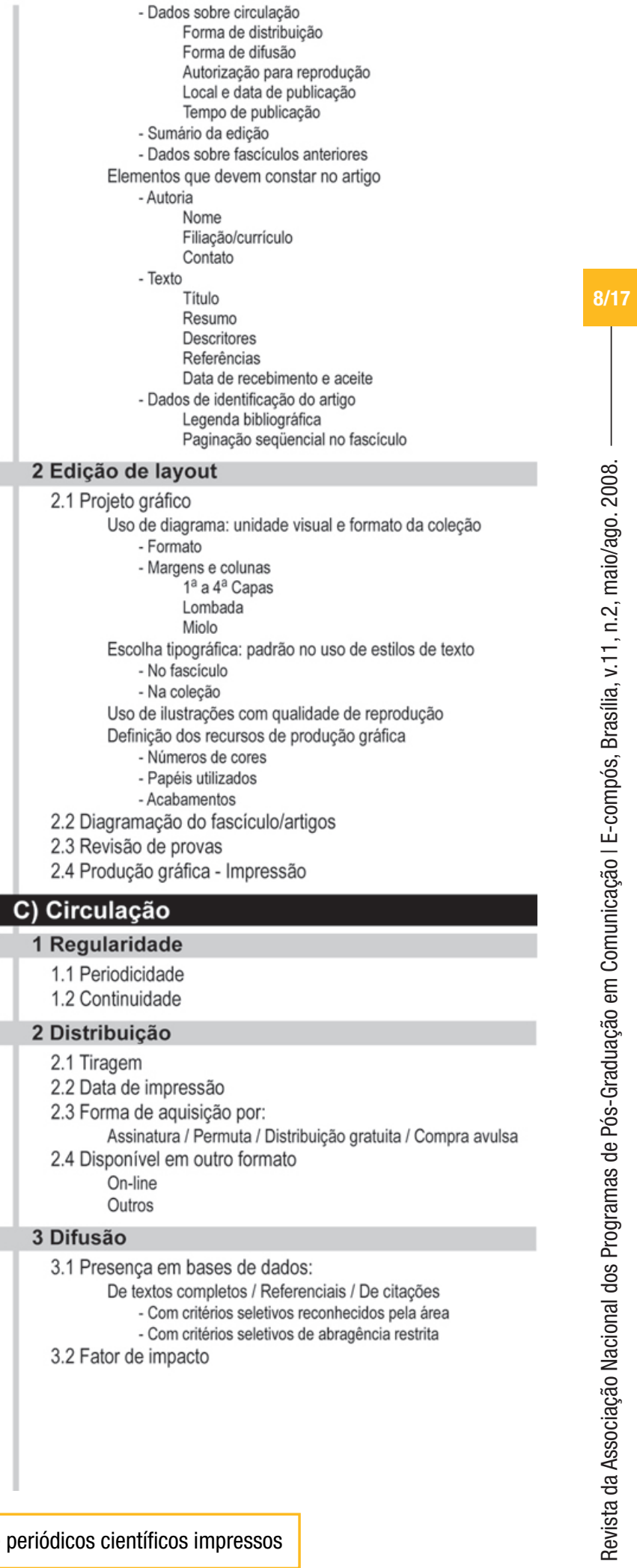




\section{A) Planejamento editorial}

\section{Gestão editorial}

1.1 Composição de corpo editorial

Comissão executiva e editor responsável

Conselho editorial com abrangência:

- Local / Nacional / Internacional

1.2 Definição de avaliadores ad hoc

\section{Infra-estrutura}

2.1 Espaço físico

2.2 Equipamentos e recursos tecnológicos

\section{Serviços técnicos especializados}

3.1 Recursos financeiros para contratação

3.2 Parcerias, fomento ou patrocinio

\section{Política editorial}

4.1 Título e subtitulo do periódico

4.2 Área de conhecimento abrangida

4.3 Projeto editorial

Missão
Periodicidade

Avaliação por pares e critérios de arbitragem

Originalidade dos artigos

Seçōes

Idiomas

Perfil de autores e leitores

Requisitos normativos

Circulação

\section{Critérios de edição (decorrentes da politica editorial)}

5.1 Diretrizes para autores

Modo de submissão

Normalização utilizada e exemplos

Formato e tamanho para documentos eletrônicos

Metadados da submissão

Direitos autorais

Documento de aprovação por comissão ética em pesquisa

5.2 Número minimo de textos por volume

5.3 Organização/edição dos conteúdos em ordem: Alfabética / Temática / Por data de aceite

5.4 Cronograma/prazos por etapa

\section{B) Fluxo editorial}

\section{Edição de texto}

1.1 Avaliação pelos pares

1.2 Mediante aceite, revisão ortográfica e gramatical

1.3 Mediante aceite, normalização técnica

Elementos que devem constar no site

- Dados de identificação do periódico

Titulo

E-ISSN e/ou ISSN

Dados para contato

- Instituição responsável

Dados institucionais

Fontes de apoio/patrocinio

- Dados sobre gestão e politica editorial

Nominata de membros

Missäo

Periodicidade

Avaliação por pares e critérios de arbitragem

Diretrizes para submissão

Propriedade do direito autoral

- Dados sobre circulaçăo

Forma de distribuição

Forma de difusão

Autorização para reprodução

Local e data de publicação

Tempo de publicação
Elementos que devem constar no fasciculo

- Sumário do fascículo

- Expediente

Dados de identificação do periódico

Dados sobre gestão e politica editorial do periódico

Dados sobre forma de circulação do periódico

Elementos que devem constar no artigo

- Autoria

Nome

Filiação/curriculo

Texto

Titulo

Resumo

Descritores

Referências

Data de recebimento e aceite

- Dados de identificação do artigo

Legenda bibliográfica

Paginação seqüencial no fascículo

Data de publicação e eventual atualização do arquivo $\mathrm{DOI}$

\section{Edição de layout}

2.1 Arquitetura da informação e interface do site Consistência entre as páginas

- Estilos de menus/barras de navegação

- Estilos de texto

Estilos de cores e imagens

- Estilos de link

Tipos de recursos utilizados pelos artigos

- Texto

- Imagem fixa

- Imagem em movimento

- Áudio

- Outros

Formato dos fasciculos e artigos

Sistema de busca

Ferramentas contextuais

Acessibilidade

2.2 Diagramação do fasciculo/artigos

2.3 Revisão de provas

2.4 Disponibilização on-line/publicação

\section{C) Circulacão}

1 Regularidade

1.1 Periodicidade

1.2 Continuidade

\section{Distribuição - Formas de acesso}

2.1 Livre (protocolo OAI-PHM)

2.2 Aberto por site próprio

2.3 Mala direta

2.4 Assinatura

2.5 Disponivel em outro formato Impresso

Outros

3 Difusão

3.1 Presença em bases de dados:

De textos completos / Referenciais / De citaçōes

Com critérios seletivos reconhecidos pela área

- Com critérios seletivos de abragência restrita

3.2 Estatísticas de acesso e fator de impacto

Periódico

Fascículos

Artigos

- Consulta

- Download 
planejamento editorial, o fluxo editorial e a circulação - que visam assegurar a qualidade da produção de um periódico científico.

Realizar o planejamento editorial de uma publicação impressa significa pensar na gestão editorial do título, na infra-estrutura básica para sua implementação e manutenção, nos serviços técnicos necessários, na política editorial a ser adotada e nos critérios de edição a serem utilizados ${ }^{4}$. A gestão editorial do periódico contempla 0 estabelecimento de um corpo editorial: a definição da comissão executiva e do editor responsável - que gerenciarão as etapas de produção da publicação -, e também do conselho editorial - constituído de especialistas reconhecidos que são os responsáveis científicos da publicação. 0 passo seguinte será a definição de avaliadores ad hoc para o periódico.

A preocupação com a infra-estrutura do processo de edição se reflete na previsão do espaço físico a ser utilizado, dos equipamentos e recursos tecnológicos prioritários -computadores de mesa, impressoras, scanners, softwares de edição de texto e de layout, navegador web, instalação de rede informática, contratação de servidor seguro para arquivamento e publicação de arquivos. Ao contratar serviços técnicos especializados, devese pensar nos recursos financeiros disponíveis, possibilidade de parcerias, verbas de fomento ou patrocínio para sua realização.

A definição da política editorial pressupõe a escolha do título e subtítulo do periódico, a área de conhecimento abrangida e o projeto editorial da publicação - no qual são descritos a sua missão, periodicidade, avaliação por pares, critérios de arbitragem, exigência de originalidade dos artigos, seções, idiomas, perfil de autores e leitores, requisitos normativos e dados sobre a circulação da publicação.

Os critérios de edição incluem as diretrizes para os autores. São orientações que garantem transparência ao processo de edição, explicando o modo de submissão dos artigos e a normalização utilizada pelo periódico. Sugerese a inserção de alguns exemplos de aplicação, formato e tamanho para textos e ilustrações, a explicitação dos direitos autorais e a solicitação de documento de aprovação por comissão ética de pesquisa quando for 0 caso. Em cada edição, é preciso respeitar um número mínimo

0 novo sistema de avaliação dos periódicos científicos a ser implementado parte de diretrizes comuns a todas as áreas, mas que estão sendo especificadas tendo em vista os critérios específicos de cada campo. Existem critérios mínimos para que uma revista se enquadre como periódico científico que são: Editor Responsável; Comissão Editorial que auxilie o Editor na tomada de decisões; Conselho Editorial (Conselho Consultivo) formado por pesquisadores de diferentes instituições; registro de ISSN; linha editorial definida (expediente: missão, foco temático, periodicidade e forma de avaliação/revisão); normas de submissão claras; periodicidade regular definida; avaliação dos originais realizada por membros do Conselho Editorial (Conselho Consultivo) ou pareceristas ad hoc; publicação de contribuições na forma de artigos assinados; indicação da titulação e afiliação institucional dos autores; indicação da titulação e afiliação institucional dos membros do Conselho Editorial (Conselho Consultivo) ou dos pareceristas ad hoc; título, resumo e palavras-chave no mínimo em dois idiomas, sendo um deles na língua do periódico; e data de recebimento e aceitação de cada artigo. 
de textos por volume, e seguir uma estratégia de organização/edição dos conteúdos - ordem alfabética, temática ou por data de aceite -, além de um rigoroso cronograma/prazos para cada etapa do processo editorial, garantindo pontualidade.

0 fluxo editorial é composto das etapas de edição de texto e edição de layout. A edição de texto de cada número tem início com a avaliação pelos pares dos originais submetidos. Uma vez aceito um artigo para publicação, iniciam-se a revisão ortográfica e gramatical, bem como a normalização técnica das informações que devem constar em cada texto. As informações do fascículo devem ser revisadas e normalizadas quando já estiver decidido quantos e quais artigos entrarão naquele número.

A etapa de edição de layout começa na definição do projeto gráfico da publicação - onde são propostos um diagrama/grid para o periódico, a tipografia, os estilos para ilustrações (tabelas, quadros, fotos) e os recursos de produção a serem utilizados. Trata-se de um conjunto de características que proporcionam a unidade visual da coleção. Na revista impressa, a capa é responsável por assegurar o primeiro contato do leitor com o periódico. É o espaço em que a opção por um projeto que enfatize recursos como cores ou imagens, por exemplo, resulte em um apelo também estético no âmbito de um tipo de publicação em que a informação é prioritária. Com o projeto gráfico determinado - o que pode ocorrer concomitantemente à definição do projeto editorial do periódico - e a edição de texto concluída, é o momento da diagramação dos fascículos/artigos - etapa que consiste na distribuição dos textos e ilustrações nas páginas, a partir das especificações do projeto gráfico. A revisão das provas é feita após a conclusão da diagramação, podendo ser realizada em diversas fases, a partir da leitura do revisor e das sucessivas correções nos arquivos do layout. A produção gráfica - impressão - tem início com a aprovação do layout de todas as páginas pelo editor responsável.

A circulação é estratégica para a consolidação de um periódico, sendo decisiva a definição de sua regularidade, distribuição e difusão. Para que se mantenha constante e atinja o públicoalvo, é preciso prever uma periodicidade possível de ser mantida ao longo do tempo, garantindo continuidade à coleção. A periodicidade mínima indicada pela CAPES é de dois números por ano. A distribuição, por sua vez, reflete a tiragem necessária para cada número. Percebe-se indispensável informar a data de impressão da edição no próprio fascículo, suas possíveis formas de aquisição - assinatura, permuta, distribuição gratuita, compra avulsa -, bem como se está disponível em outro formato - on-line, por exemplo.

Pensar a difusão de uma publicação impressa consiste em assegurar sua presença em bases de dados - que podem ser de textos completos, referenciais e de citações (mantendo critérios seletivos reconhecidos pela área, ou de 
abrangência restrita). 0 fator de impacto dos periódicos é obtido dividindo-se o número total de citações dos artigos acumulados nos últimos dois anos pelo total acumulado de artigos publicados pela revista no referido período. 0 fator de impacto ajuda a ponderar a importância relativa do periódico, especialmente quando comparado com outros na mesma área. Para as áreas do conhecimento em que esse indicador possui maior relevância nos sistemas de avaliação de produção acadêmica, torna-se essencial pensar em estratégias para elevar esse índice. ${ }^{5}$

Nos procedimentos de edição de uma publicação periódica on-line, mantêm-se as principais etapas apresentadas anteriormente para edições impressas. Uma das principais diferenças aparece na edição de layout, onde 0 trabalho de projeto gráfico é substituído pela definição da arquitetura da informação e interface do site - com a proposta de consistência entre as páginas, tipos de recursos utilizados pelos artigos, formato dos fascículos e textos (PDF, html), sistemas de busca, ferramentas contextuais (mecanismos de recuperação contextualizada do conteúdo) e acessibilidade.

Cuidados devem ser tomados com relação à distribuição, ou formas de acesso, da publicação on-line, que mantém diferenças em relação aos volumes impressos. A preocupação com 0 acesso livre, não necessariamente sem custo - uma vez que os valores de produção da publicação podem ser repassados para os autores, por exemplo
-, significa pensar na disponibilização livre na Internet do periódico, de modo que qualquer pessoa possa lê-lo, baixá-lo, copiá-lo, distribuí-lo. É preciso definir também se 0 conteúdo estará aberto por site próprio e não por um sistema integrado; se 0 envio das edições será feito por mala direta ou por solicitação de assinatura para acesso aos artigos. Ainda em relação à distribuição de periódicos on-line, é importante saber se 0 título também estará disponível em outro formato.

Cabe destacar que se a visibilidade dos periódicos depende também da capacidade de ser acessado em bases de dados e índices, questões tecnológicas são determinantes na localização das informações, geralmente realizadas através de mecanismos de busca e indexação. Para facilitar esse processo, pode-se associar metadados aos documentos, que são dados que descrevem informações sobre cada recurso digital. Estes têm a função de facilitar a recuperação de informações eletrônicas, fornecendo meios de identificação e organização, tornando possível a associação de fontes diferenciadas e heterogêneas. No âmbito da edição de periódicos eletrônicos, portanto, o termo visibilidade não se restringe apenas a características relacionadas à clareza do layout de um documento. Além do web design, a acessibilidade e 0 desenvolvimento de recursos otimizados para serviços de pesquisa compõem um conjunto de fatores que devem fazer parte do 
planejamento editorial de uma publicação.

A adoção de um sistema como o Open Journal Systems (0JS) da British Columbia University - traduzido e adaptado no Brasil pelo Instituto Brasileiro de Informação em Ciência e Tecnologia (IBICT) e que deu origem ao Sistema Eletrônico de Editoração de Revistas (SEER) - permite que um periódico ganhe rapidez e transparência nos procedimentos editoriais, desde a submissão e avaliação até a publicação on-line e indexação. Ligado à iniciativa de acesso livre à informação científica e ao utilizar o protocolo OAI-PMH Open Archives Initiative Protocol for Metadata Havesting -, o sistema possibilita o intercâmbio de metadados, ferramentas de apoio à pesquisa, assim como mecanismos para preservação dos conteúdos.

Segundo Packer e Meneghini (2006, p. 253-254), o número médio de leitura ou de artigos acessados (downloads) constitui um dado fundamental na visibilidade de um periódico na web. Quanto maior esse número, mais visível se torna a publicação on-line. Potencializar esse indicador é aumentar o número de incomming links para o periódico. Ou seja, participar de coleções internacionais de qualidade implica em usufruir do seu sistema de links. As revistas das coleções SciELO - Scientific Eletronic Library Online ${ }^{6}$ - apresentam uma média de dois milhões de visitas por mês, muitas delas provenientes de índices e buscadores como LILACS, Web of Science, Portal Capes, PubMed, entre outros. 0 fator de impacto da maioria dos periódicos SciEL0 aumentou a partir da existência da coleção. (GRUSZYNSKI; GOLIN, 2007)

\section{Considerações finais}

A produção editorial na contemporaneidade revela as tensões existentes entre 0 conhecido mundo impresso e seus pacotes determinados de informação, e o espaço on-line como um contínuo informativo. Questões arraigadas vêm sendo redimensionadas nesse ambiente, assim como a própria velocidade de validação e circulação do conhecimento. 0 chamado sistema on the fly, ao oferecer a possibilidade de divulgar um texto assim que ele é liberado pelo peer review, pode suplantar a lenta circulação, a eventual falta de pontualidade e os limites típicos da ciência organizada em fascículos de papel. Para Meadows (2001), mesmo que o periódico eletrônico necessite reproduzir as rotinas que abalizaram sua reputação e credibilidade na cultura letrada, aumentam-se cada vez mais, no cenário digital, os desafios em relação à filtragem daquilo que será disponibilizado on-line, dado o alcance e 0 efeito multiplicador da leitura em rede.

Projeto desenvolvido pela Fundação de Apoio à Pesquisa do Estado de São Paulo (FAPESP), pelo CNPq e pelo Centro LatinoAmericano e do Caribe de Informação e Ciências da Saúde (BIREME). Trata-se de um agregador não-comercial para consulta a periódicos brasileiros e estrangeiros, selecionados a partir de critérios internacionais de qualidade. A rede ibero-americana de acesso aberto, liderada pelo Brasil e pelo Chile, publica indicadores bibliométricos similares aos do Journal Citation Reports (JCR) do ISI (Institute for Scientific Information). Apresenta sistema de metadados, links com outras fontes de informação, estatísticas de uso e citações e fator de impacto. No Brasil, serve como instância seletiva de indexação complementar, favorecendo a entrada dos periódicos nacionais em indicadores internacionais de referência. 
Nesse quadro de amplas e complexas mudanças, os roteiros apresentados representam uma estratégia provisória de produção editorial que entende que o suporte eletrônico exige muito mais do que uma mera transposição do impresso para o digital. Cabe lembrar, por fim, que essa questão não se restringe apenas à escolha de formatos e de estratégias de comunicação. Passa também, a longo prazo, por uma mudança de hábitos por parte dos pesquisadores, geralmente conservadores em relação aos modelos consagrados de sistematização, divulgação e circulação de seus trabalhos.

\section{Referências bibliográficas}

BIOJONE, Mariana Rocha. Os periódicos científicos na comunicação da ciência. São Paulo: Educ/Fapesp, 2003.

BOURDIEU, Pierre. 0 campo científico. In: ORTIZ, Renato (Org.) Pierre Bourdieu. São Paulo: Ática, 1983. BRAGANÇA, Aníbal. Sobre o editor: notas para sua história. Em Questão: Revista da Faculdade de Biblioteconomia e Comunicação da UFRGS, Porto Alegre, v. 11, n. 2, p.219-237, jul./dez. 2005.

BURKE, Peter. Uma história social do conhecimento: de Gutenberg a Diderot. Rio de Janeiro: Jorge Zahar, 2003.

CHARTIER, Roger. (Org.). Práticas de leitura. São Paulo: Liberdade, 1996.

FERREIRA, S.M.S.P. Fator de impacto da produção científica da área de ciências da comunicação: um longo caminho a ser percorrido. In: Pinho, J.B., ed. Comunicação brasileira no século XXI - Intercom: ação, reflexão. São Paulo: Intercom, 2007. p. 125-153. (Coleção Verde-amarela, vol.2 - A clava forte). ; TARGINO, Maria das Graças (Orgs.). Preparação de revistas científicas: teoria e prática. São Paulo: Reichmann \& Autores, 2005.
GRUSZYNSKI, Ana Cláudia; GOLIN, Cida. Periódicos científicos e a visibilidade da ciência na web: estudo de caso na UFRGS. DataGramaZero, <http://www. datagramazero.org.br>, v. 8, n. 3, jun. 2007. Acesso em: 03 abr. 2008.

Periódicos científicos nos suportes impresso e eletrônico: apontamentos para um estudopiloto na UFRGS. Eptic, <http://www.eptic.com.br>, v. VIII, n. 2, 2006. Acesso em: 10 abr. 2008.

; LUCCHESE, Alexandre. Desafios para a comunicação da ciência: um estudo sobre os periódicos científicos e eletrônicos da UFRGS. In: Anais do XXX CONGRESSO BRASILEIRO DE CIÊNCIAS DA COMUNICAÇÃO INTERCOM, 2007, Santos.

HOUGHTON, Bernard. Scientific Periodicals: their historical development, characteristics and control. Londres: The Central Press, 1975.

KRZYZANOWSKI, Rosali Favero; FERREIRA, Maria Cecília Gonzaga. Avaliação de Periódicos Científicos e Técnicos Brasileiros. Ciência da Informação, Brasília, DF, v.27, n.2, p.165-175, maio/ago. 1998.

LANCASTER, F. W. The evolution of electronic publishing. In: Library Trends, Illinois, v. 43, n.4, p. 518-524. 1995.

LAWRENCE, Steve. Free online availability substantially increases a paper's impact. Nature Debate. Disponível em: <http:/www.nature.com/nature/debates/e-access/ Articles/lawrence.html>. Acesso em: 31 maio 2001.

LYONS, Martyn. A palavra impressa: histórias da leitura no século XIX. Rio de Janeiro: Casa da Palavra, 1999.

MARCHIORI, Patrícia Z.; ADAMI, Anderson. Autoria e leitura de artigos por docentes pesquisadores: motivações e barreiras. In: FERREIRA, Sueli M. S. P.; TARGINO, Maria das Graças (Orgs.). Preparação de revistas científicas: teoria e prática. São Paulo: Reichmann \& Autores, 2005, pp. 73-100. 
MEADOWS, Arthur Jack. A Comunicação Científica. (tradução de Antonio Agenor Briquet de Lemos) Brasília: Briquet de Lemos, 1999.

Os periódicos científicos e a transição do meio impresso para o eletrônico. Revista de Biblioteconomia de Brasília, v. 25, n.1, p.5-14, jan./jun. 2001.

MENDONÇA, T. C.; FACHIN, Gleisy Regina Bories; VARVAKIS, G., Padronização de periódicos científicos en línea: estudo aplicado na área de Biblioteconomia e Ciência da Informação. Informação \& Sociedade. Estudos, v. 16, p. 1-27, 2006

OLIVEIRA, Érica. Produção científica nacional na área de geociências: análise de critérios de editoração, difusão e indexação em bases de dados. Ciência da Informação, Brasília, v.34, n.2, p.34-42, maio/ago. 2005.

OLSON, David. 0 mundo de papel: as implicações conceituais e cognitivas da leitura e escrita. São Paulo: Ática, 1997.

PACKER, Abel Laerte; MENEGHINI, Rogério. Visibilidade da produção científica. In: Poblacion, Dinah Aguiar (org). Comunicação \& produção científica: contexto, indicadores e avaliação. São Paulo: Angellara, 2006. p. 237-259.

SABBATINI, Marcelo. Qualidade da informação nas publicações científicas eletrônicas na Internet: desafios e propostas. Teoría de la educación y cultura en la sociedad de la información, Salamanca, v.2, 2000. Disponível em: <http://www3. usal.es/ teoriaeducacion/rev_numero_02/n2_art_ sabbatini.htm>. Acesso em: 03 abr. 2006.

SARMENTO E SOUZA, Maria Fernanda; FORESTI, Miriam C. P. P.; VIDOTTI, Silvana A. B. G. Periódicos científicos eletrônicos: critérios de qualidade. Mudanças no processo de comunicação científica: a alternativa dos repositórios institucionais. In: VIDOTTI, Silvana A. B. G. (org). Tecnologia e conteúdos informacionais: abordagens teóricas e práticas. São Paulo: Polis, 2004, p.153-168.
STUMPF, Ida Regina Chitto. Passado e futuro das revistas cientificas. Ciência da Informação, Brasília, v. 25, n. 3 , p. 383-386. 1996.

Periódicos científicos. Documentos ABEBD,

8. Porto Alegre: Associação Brasileira de Ensino em Biblioteconomia e Documentação, 1998.

TARGINO, M. G. Comunicação científica na sociedade tecnológica: periódicos eletrônicos em discussão. In:

Comunicação \& Sociedade, São Paulo, n.31, 1999.

TRZESNIAK, Piotr. A avaliação de revistas eletrônicas para órgãos de fomento: respondendo ao desafio.

In: CONFERÊNCIA IBEROAMERICANA DE PUBLICAÇÕES ELETRÔNICAS NO CONTEXTO DA COMUNICAÇÃO CIENTÍFICA, 1., 2006, Brasília.

Anais... Brasília: Universidade de Brasília, 2006. Disponível em: <http://portal.cid.unb.br/CIPECCbr/ viewpaper.php?id=26\&print $=1 \&$ PHPSESSID $=8 \mathrm{f} 99710 \mathrm{e}$ dd3789ada04ed656dc2687b8>. Acesso em: 18 dez. 2006 


\section{Editorial production and scientific communication: a proposal for the edition of scientific journals}

\section{Abstract}

The contemporary editorial production reveals the tensions between the traditional print world, with its physical limits of information, and the on-line space as a continuous place for information. Analyzing the scenario of scholarly communication, this article presents the final results of the survey "The communicative elements of the scientific journals and the relationship with the printed and on-line environments: pilot study at UFRGS". From the perspective of editorial production, it proposes two roadmaps for the guidance of editorial committees in publishing, consolidating and qualifying printed and electronic scientific journals.

\section{Keywords}

Editorial production. Scholarly communication. Scientific journals. UFRGS.

\section{Producción editorial y comunicación científica: una propuesta para la edición de revistas científicas}

\section{Resumen}

La producción editorial contemporánea revela las tensiones existentes entre el tradicional mundo impreso, con límites físicos de información, y el espacio en línea como un continuo informativo. Problematizando el escenario de la comunicación científica, este artículo presenta los resultados finales de la investigación Los elementos comunicacionales de los periódicos científicos y la relación con los soportes impreso y en línea: estudio piloto en la UFRGS. A partir de la perspectiva de la producción editorial, propone dos caminos para orientación de las comisiones editoriales en la edición, consolidación y calificación de periódicos científicos impresos y electrónicos.

\section{Palabras clave}

Producción editorial. Comunicación científica. Periódicos científicos. UFRGS. 


\section{Expediente}

A revista E-Compós é a publicação científica em formato eletrônico da Associação Nacional dos Programas de Pós-Graduação em Comunicação (Compós). Lançada em 2004, tem como principal finalidade difundir a produção acadêmica de pesquisadores da área de Comunicação, inseridos em instituições do Brasil e do exterior.
E-COMPÓS I www.e-compos.org.br I E-ISSN 1808-2599

Revista da Associação Nacional dos Programas de Pós-Graduação em Comunicação. Brasília, v.11, n.2, maio/ago. 2008

A identificação das edições, a partir de 2008 passa a ser volume anual com três números.

\section{CONSELHO EDITORIAL}

\section{Afonso Albuquerque}

Universidade Federal Fluminense, Brasil

Alberto Carlos Augusto Klein

Universidade Estadual de Londrina, Brasi

Alex Fernando Teixeira Primo

Universidade Federal do Rio Grande do Sul, Brasi

Alfredo Vizeu

Universidade Federal de Pernambuco, Brasil

Ana Carolina Damboriarena Escosteguy

Pontifícia Universidade Católica do Rio Grande do Sul, Brasil

Ana Silvia Lopes Davi Médola

Universidade Estadual Paulista, Brasil

André Luiz Martins Lemos

Universidade Federal da Bahia, Brasil

Ângela Freire Prysthon

Universidade Federal de Pernambuco, Brasi

Antônio Fausto Neto

Universidade do Vale do Rio dos Sinos, Brasil

Antonio Carlos Hohlfeldt

Pontifícia Universidade Católica do Rio Grande do Sul, Brasil

Arlindo Ribeiro Machado

Universidade de São Paulo, Brasil

César Geraldo Guimarães

Universidade Federal de Minas Gerais, Brasi

Cristiane Freitas Gutfreind

Pontifícia Universidade Católica do Rio Grande do Sul, Brasi

Denilson Lopes

Universidade Federal do Rio de Janeiro, Brasil

Eduardo Peñuela Cañizal

Universidade Paulista, Brasil

Erick Felinto de Oliveira

Universidade do Estado do Rio de Janeiro, Brasil

Francisco Menezes Martins

Universidade Tuiuti do Paraná, Brasil

Gelson Santana

Universidade Anhembi/Morumbi, Brasil

Hector Ospina

Universidad de Manizales, Colômbia

leda Tucherman

Universidade Federal do Rio de Janeiro, Brasil

Itania Maria Mota Gomes

Universidade Federal da Bahia, Brasil

Janice Caiafa

Universidade Federal do Rio de Janeiro, Brasil

Jeder Silveira Janotti Junior

Universidade Federal da Bahia, Brasil
John DH Downing

University of Texas at Austin, Estados Unidos

José Luiz Aidar Prado

Pontifícia Universidade Católica de São Paulo, Brasil

José Luiz Warren Jardim Gomes Braga

Universidade do Vale do Rio dos Sinos, Brasi

Juremir Machado da Silva

Pontifícia Universidade Católica do Rio Grande do Sul, Brasil

Lorraine Leu

University of Bristol, Grã-Bretanha

Luiz Claudio Martino

Universidade de Brasília, Brasil

Maria Immacolata Vassallo de Lopes

Universidade de São Paulo, Brasil

Maria Lucia Santaella

Pontifícia Universidade Católica de São Paulo, Brasil

Mauro Pereira Porto

Tulane University, Estados Unidos

Muniz Sodre de Araujo Cabral

Universidade Federal do Rio de Janeiro, Brasil

Nilda Aparecida Jacks

Universidade Federal do Rio Grande do Sul, Brasil

Paulo Roberto Gibaldi Vaz

Universidade Federal do Rio de Janeiro, Brasil

Renato Cordeiro Gomes

Pontifícia Universidade Católica do Rio de Janeiro, Brasil

Ronaldo George Helal

Universidade do Estado do Rio de Janeiro, Brasil

Rosana de Lima Soares

Universidade de São Paulo, Brasil

Rossana Reguillo

Instituto Tecnológico y de Estudios Superiores do Occidente, México

Rousiley Celi Moreira Maia

Universidade Federal de Minas Gerais, Brasil

Sebastião Carlos de Morais Squirra

Universidade Metodista de São Paulo, Brasil

Simone Maria Andrade Pereira de Sá

Universidade Federal Fluminense, Brasil

Suzete Venturelli

Universidade de Brasília, Brasil

Valério Cruz Brittos

Universidade do Vale do Rio dos Sinos, Brasil

Veneza Mayora Ronsini

Universidade Federal de Santa Maria, Brasil

Vera Regina Veiga França

Universidade Federal de Minas Gerais, Brasil
COMISSÃO EDITORIAL

Ana Gruszynski I Universidade Federal do Rio Grande do Sul, Brasil João Freire Filho I Universidade Federal do Rio de Janeiro, Brasil Rose Melo Rocha I Escola Superior de Propaganda e Marketing, Brasil

\section{CONSULTORES AD HOC}

Aníbal Bragança I Universidade Federal Fluminense, Brasil Gisela Castro I Escola Superior de Propaganda e Marketing, Brasil

Gislene Silva I Universidade Federal de Santa Catarina, Brasil

Maria Helena Weber I Universidade Federal do Rio Grande do Sul, Brasil

Rosana de Lima Soares I Universidade de São Paulo, Brasil

Tania Hoff I Escola Superior de Propaganda e Marketing, Brasil

REVISÃO DE TEXTO E TRADUÇÃo I Everton Cardoso

ASSISTÊNCIA EDITORIAL E EDITORAÇÃO ELETRÔNICA I Raquel Castedo
COMPós I www.compos.org.br

Associação Nacional dos Programas de Pós-Graduação em Comunicação

Presidente

Erick Felinto de Oliveira

Universidade do Estado do Rio de Janeiro, Brasil erickfelinto@uol.com.br

Vice-presidente

Ana Silvia Lopes Davi Médola

Universidade Estadual Paulista, Brasil

asilvia@faac.unesp.br

Secretária-Geral

Denize Correa Araújo

Universidade Tuiuti do Paraná, Brasil

denizearaujo@hotmail.com 